\title{
Capsule Endoscopy in Henoch-Schönlein Purpura
}

\section{E. Skogestad}

Department of Internal Medicine, Sykehuset Innlandet Lillehammer, Lillehammer, Norway

\section{Corresponding Author}

\section{E. Skogestad}

Department of Internal Medicine, Sykehuset Innlandet Lillehammer 2629 Lillehammer

Norway

Fax: $\quad$ + 47-61272039

E-mail: erik.skogestad@sykehusetinnlandet.no
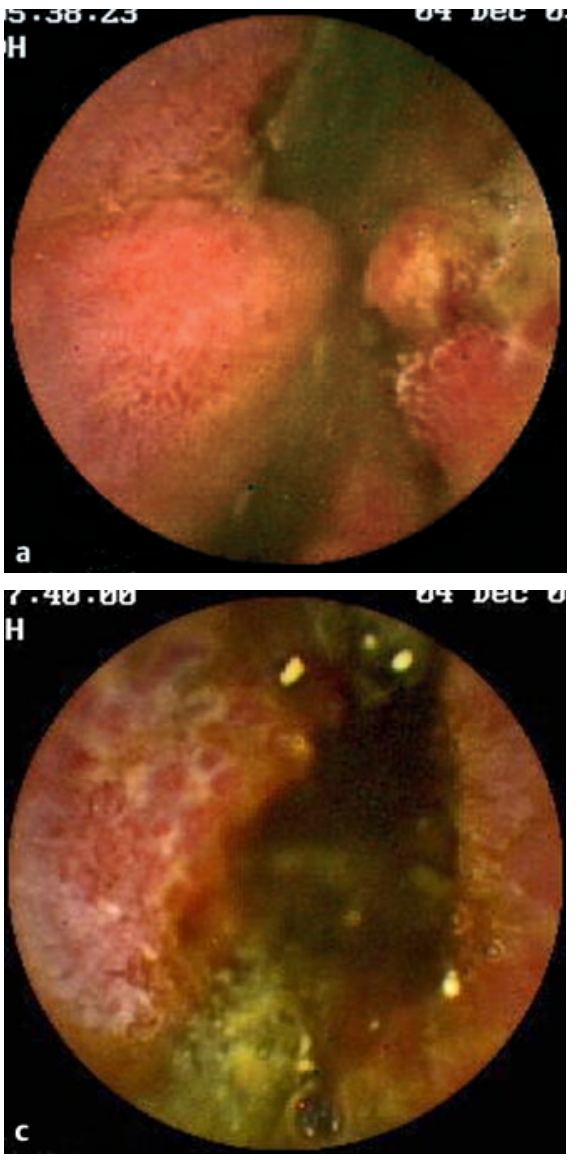

Figure 1 The small bowel has been the "Dark Continent" for gastroenterologists. A 32-yearold man with Henoch-Schönlein purpura (HSP) presented with purpura, scrotal pain, arthralgia, nephritis, and abdominal pain. HSP is an IgA-mediated autoimmune vasculitis characterized by deposits of IgA in the vascular wall. Skin biopsies revealed a leukocytoclastic vasculitis (consistent with HSP). Capsule endoscopy showed extensive mucosal inflamma-
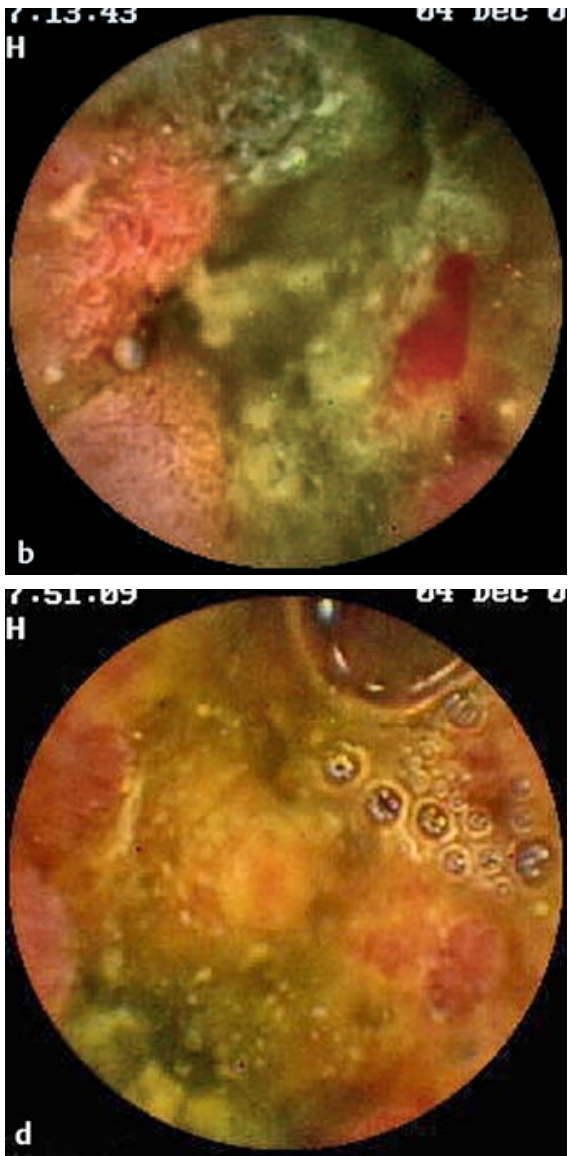

tion throughout the entire small bowel (duodenojejunoileitis), with redness, swelling, and ulcerations with fibrin deposits and sparse areas of spontaneous bleeding. It is not surprising that the patient with HSP has abdominal pain. Image $\mathbf{a}$ is a view from the mid-jejunum and images $\mathbf{b}-\mathbf{d}$ are from the ileum. Images of the small-bowel mucosa in patients with HSP have not been reported previously. 